\title{
Societal landslide and flood risk in Italy
}

\author{
P. Salvati, C. Bianchi, M. Rossi, and F. Guzzetti \\ Istituto di Ricerca per la Protezione Idrogeologica, Consiglio Nazionale delle Ricerche, via Madonna Alta 126, \\ 06128 Perugia, Italy
}

Received: 5 January 2010 - Accepted: 24 February 2010 - Published: 16 March 2010

\begin{abstract}
We assessed societal landslide and flood risk to the population of Italy. The assessment was conducted at the national (synoptic) and at the regional scales. For the assessment, we used an improved version of the catalogue of historical landslide and flood events that have resulted in loss of life, missing persons, injuries and homelessness in Italy, from 1850 to 2008. This is the recent portion of a larger catalogue spanning the 1941-year period from 68 to 2008 . We started by discussing uncertainty and completeness in the historical catalogue, and we performed an analysis of the temporal and geographical pattern of harmful landslide and flood events, in Italy. We found that sites affected by harmful landslides or floods are not distributed evenly in Italy, and we attributed the differences to different physiographical settings. To determine societal risk, we investigated the distribution of the number of landslide and flood casualties (deaths, missing persons, and injured people) in Italy, and in the 20 Italian Regions. Using order statistics, we found that the intensity of a landslide or flood event - measured by the total number of casualties in the event - follows a general negative power law trend. Next, we modelled the empirical distributions of the frequency of landslide and flood events with casualties in Italy and in each Region using a Zipf distribution. We used the scaling exponent $s$ of the probability mass function (PMF) of the intensity of the events, which controls the proportion of small, medium, and large events, to compare societal risk levels in different geographical areas and for different periods. Lastly, to consider the frequency of the events with casualties, we scaled the PMF obtained for the individual Regions to the total number of events in each Region, in the period 1950-2008, and we used the results to rank societal landslide and flood risk in Italy. We found that in the considered period societal landslide risk is largest in Trentino-Alto Adige and Campania, and societal flood risk is highest in Piedmont and Sicily.
\end{abstract}

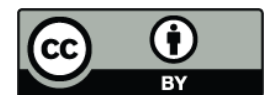

Correspondence to: P. Salvati (paola.salvati@irpi.cnr.it)

\section{Introduction}

The purpose of risk analysis is to determine the probability that a specific hazard will cause harm. This can be achieved by investigating the frequency of the damaging events and the intensity of the consequences. The number of fatalities (deaths and missing persons) and the number of casualties (deaths, missing persons, and injured people) are a direct, quantitative measure of the intensity of a disaster, and can be used to evaluate individual and societal risk quantitatively (Fell and Hartford, 1997; Guzzetti et al., 2005a, b).

Individual-risk criteria are expressed using mortality (or death) rates, which are a measure of the number of fatalities in a population, scaled to the size of the population, per unit time. Typically, when studying natural or technological hazards, the number of deaths per 100000 people in a period of one year gives mortality. Societal-risk criteria are established constructing frequency-consequences plots, on which the number of losses in each event is plotted versus the frequency of the event, and investigating the relationships between the frequency of the events and their intensity (Fell and Hartford, 1997; Guzzetti et al., 2005a, b).

In Italy, landslides and floods kill or injure people almost every year. For this country, individual and societal landslide risk levels were defined by Guzzetti (2000), and revised by Salvati et al. (2003) and Guzzetti et al. (2005a, b). Flood risk levels were established by Salvati et al. (2003), and revised by Guzzetti et al. (2005a, b). We use an improved version of the catalogue of landslides and floods with human consequences in Italy (Salvati et al., 2003; Guzzetti et al., 2005a, b) to update the existing national estimates, and to obtain first regional estimates, of societal landslide and flood risk in Italy.

In this paper, we first describe the new catalogue, and we update previous analyses of the temporal and geographical patterns of landslides and floods with human consequences in Italy (Guzzetti et al., 2005a, b). Next, using order statistics, we study the distribution of the number of landslide and flood casualties (which encompass deaths, missing persons

Published by Copernicus Publications on behalf of the European Geosciences Union. 
and injured people) in Italy, and in the 20 Italian Regions. Then, modelling the empirical distributions of the frequency of the landslide and flood events with casualties, we determine societal risk levels in Italy and in each Region, and we rank the Regions on their landslide and flood risk to the population. We conclude by discussing the results obtained, in view of their geomorphological (hydrological, geological) relevance.

\section{New catalogue of landslides and floods with human consequences in Italy}

In Italy, information exists on the direct damage to the population caused by different natural hazards, including landslides and floods (Guzzetti, 2000; Salvati et al., 2003; Guzzetti et al., 2005a, b). For this work, we have updated the catalogue of landslides and floods with direct human consequences in Italy compiled by Salvati et al. (2003), and revised by Guzzetti et al. (2005b). The new catalogue covers the 1941-year period from 68 to 2008, and lists 3139 landslide events and 2595 flood events that have resulted in deaths, missing persons, injured people, and homelessness.

To update the historical catalogue, we searched new bibliographical and archive sources, we examined five regional catalogues of historical landslide and flood events available on the Internet, and we re-examined some of the sources of information used by Salvati et al. (2003) and Guzzetti et al. (2005b), including the national catalogue of landslide and flood events in Italy (Guzzetti et al., 1994; Guzzetti and Tonelli, 2004). The new sources of historical information include regional and local history books, transcriptions or translations of old chronicles, and reports prepared by regional and local technical offices to describe the effects of single events and their consequences. The old chronicles provided information on events in the early part of the catalogue, chiefly for limited geographical areas. The five regional catalogues provided abundant and accurate information on the date of occurrence of the events, the exact or approximate location of the events, and the type and the extent of the damage. The event reports provided accurate information for a limited number of events. For a few individual events, new or updated information was obtained searching the Internet.

\subsection{Uncertainty in the historical information}

For some event in the catalogue, uncertainty exists on the consequences. For a few events, a discrepancy exists in the number of deaths, missing persons, injured people and homeless reported by different sources. The differences depend primarily on the fact that the exact number of the consequences is often available only at the end of a search-andrescue operation, from a few days to weeks after the onset of the event. During this period, newspapers and even official reports may provide different and changing figures. Similarly, the location of a few fatal events is uncertain, depending on the fact that the site where people were hit by a landslide or overrun by an inundation, and the location where the bodies were found, are different and distant.

In the catalogue, information on the location and damage caused by recent landslide and flood events is generally accurate. Geographical accuracy decreases going back in the past. Historical documents and chronicles were more accurate in providing figures for the casualties caused by landslides, than those caused by floods. Mass movements were easier than inundations to identify geographically, chiefly because the spatial extent of the damage caused by landslides is more limited than the damage caused by floods. Even though landslides that occurred on slopes were undoubtedly reported as such, recognition of an event as a landslide was not always easy, particularly in the oldest reports. The definition of the type of event was more uncertain when the mass movement was a debris flow, or if it occurred along the drainage network. When widespread (regional) flooding caused fatalities, a total (cumulative) number was given, including deaths caused by others hazardous events e.g., diseases, famine. When a rainfall event affected a large geographical area, producing both landslides and floods, the effects of landslides were sometimes confused with the effects of flooding, and only the latter were reported (Guzzetti, 2000; Guzzetti et al., 2005b).

A few landslides, including the failure of natural dams, and of man-made dams and embankments, caused rapid flooding that resulted in fatalities. Following Guzzetti et al. (2005b), the damage caused by these failures was considered the indirect effect of single landslides, and the causalities were listed in the landslide catalogue. In the period 1521-2008, 14 landslide events resulted in indirect flood casualties. Of these events, five $(0.4 \%)$ occurred in the period 1850-2008. We take this as an indication that landslide events with indirect flood casualties are uncommon in Italy.

For the very old events in the catalogue, it was not possible to quantify the number of deaths caused by the fatal events. For these uncertain events, the sources of information provide a qualitative description of the number of fatalities defining them as few, several, many or hundreds. This has introduced further uncertainty in the catalogue.

\subsection{Temporal analysis and completeness of the catalogue}

In the catalogue, the first landslide for which the exact number of casualties is known (24 deaths) occurred in 843 in the Piedmont Region. For floods, the oldest event for which the (approximate) number of casualties is listed (1000 deaths) occurred in 671 in the Lombardy Region.

Figure 1 portrays the temporal pattern of landslide and flood casualties in Italy. In the 1166-year period 8432008, the catalogue lists 1562 landslide events that have caused at least 15890 casualties. Similarly, in the 1338-year 

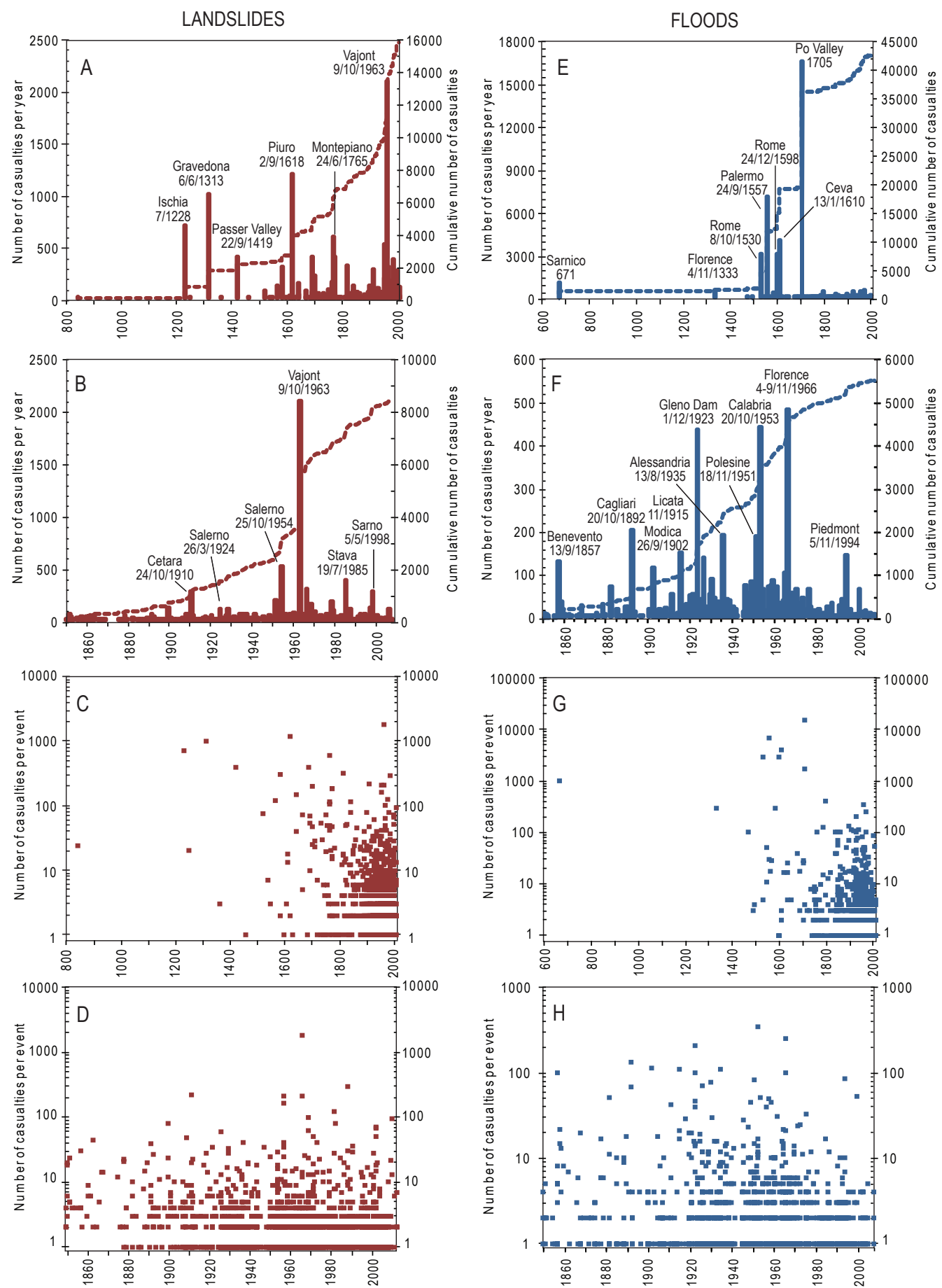

Fig. 1. Historical distribution of landslide and flood events with casualties in Italy. Data for landslides (A-D) and for floods (E-H) are shown separately. In A, B for landslides, and E, F for floods, bars show the number of casualties per year, and dashed lines show the cumulative number of casualties. Plots $\mathrm{C}, \mathrm{D}$ for landslides, and $\mathrm{G}, \mathrm{H}$ for floods show the number of casualties per event. Different time intervals are shown: A and C (landslides), 800-2008; E and G (floods), 600-2008; B and D (landslides), F and H (floods), 1850-2008.

period 671-2008, the catalogue lists 1263 flood events that have resulted in at least 42845 casualties. The total number of homeless and evacuated people caused both by landslides and floods in the 1338-year period 671-2008 exceeded
873000. This is an approximate estimate, because values listed in initial reports may be overestimated, and for many $(28.8 \%)$ records in the catalogue only qualitative figures are available. 
Table 1. Statistics of landslide and flood events with deaths, missing persons and injured people in Italy, for different periods. Fatalities encompass deaths and missing persons. Casualties encompass deaths, missing persons and injured people.

\begin{tabular}{|c|c|c|c|c|c|c|c|c|}
\hline & \multicolumn{4}{|c|}{ Landslides } & \multicolumn{4}{|c|}{ Floods } \\
\hline & $843-1849$ & $1850-1899$ & 1900-1949 & 1950-2008 & $671-1849$ & 1850-1899 & 1900-1949 & 1950-2008 \\
\hline Length of period (yr) & 1007 & 50 & 50 & 59 & 1179 & 50 & 50 & 59 \\
\hline Deaths (a) & 7477 & 614 & 1119 & 4077 & 37018 & 674 & 2319 & 1124 \\
\hline Missing persons (b) & - & - & 8 & 26 & 4 & 2 & 13 & 90 \\
\hline Injured people (c) & 5 & 49 & 406 & 2019 & 21 & 8 & 467 & 1485 \\
\hline Fatalities $(a+b)$ & 7477 & 614 & 1207 & 4103 & 37022 & 676 & 2332 & 1214 \\
\hline Casualties $(a+b+c)$ & 7487 & 663 & 1613 & 6122 & 37043 & 684 & 2799 & 2699 \\
\hline Evacuees and homeless people & 2729 & 2185 & 11026 & 177376 & 17614 & 119293 & 44653 & 497334 \\
\hline Largest number of fatalities in an event & 1200 & 81 & 220 & 1952 & 15000 & 134 & 209 & 84 \\
\hline Largest number of casualties in an event & 1200 & 81 & 200 & 2035 & 15000 & 134 & 209 & 341 \\
\hline Total number of events & 210 & 162 & 509 & 2204 & 269 & 180 & 667 & 1654 \\
\hline with known number of casualties & 107 & 82 & 360 & 967 & 115 & 95 & 337 & 613 \\
\hline with known number of fatalities & 107 & 82 & 306 & 656 & 115 & 94 & 298 & 520 \\
\hline with unknown number of casualties & 33 & 3 & 7 & 3 & 70 & 26 & 6 & 1 \\
\hline Average number of fatalities per event & 69.8 & 7.4 & 3.9 & 6.2 & 321.9 & 7.2 & 7.8 & 2.3 \\
\hline Average number of casualties per event & 69.9 & 8.0 & 4.5 & 6.3 & 322.1 & 7.2 & 8.3 & 4.4 \\
\hline
\end{tabular}

Inspection of Fig. 1 allows for two general considerations. First, the number of landslide and flood events per unit time (i.e., per year) increases with time. The increase is particularly significant after about 1700 to 1850 . Second, the severity (intensity, or magnitude) of the recorded events, measured by the number of casualties, varies with time. In the oldest section of the catalogue, the few recorded events were mainly catastrophic, while in the recent period (1850-2008) many low intensity events were listed in the catalogue. To investigate the problem, we divided the catalogue in four subsets covering different periods, and we studied the relationship between the number of reported casualties and the number of events, in each period. To better study the increase in the number of reported events after 1850, we divided the last 159-year period of the catalogue in smaller subsets of approximately equal length. The selected periods were: (i) 843-1849, (ii) 1850-1899, (iii) 1900-1949, and (iv) 19502008 for landslides, and (v) 671-1849, (vi) 1850-1899, (vii) 1900-1949, and (viii) 1950-2008 for floods (Table 1).

For both landslides and floods, the largest number of casualties was reported in the oldest portion of the catalogue (before 1850), with an average of 69.9 landslide casualties per event (in 107 events), and 322.1 flood casualties per event (in 115 events). For the most recent portion of the catalogue (1950-2008), the total number of landslide casualties was 6122 in 967 events, corresponding to an average of 6.3 casualties per event, and the total number of flood casualties was 2699 in 613 events, an average of 4.4 flood casualties per event. The difference in the average number of casualties per event suggests that the oldest events reported in the catalogue were particularly catastrophic, but also that the old part of the catalogue is incomplete for the medium and low intensity events.
Our historical catalogue is a non-instrumental record of past landslide and flood events that have resulted in casualties in Italy. Non-instrumental records of natural events, including landslides and floods, are always affected by incompleteness, which is difficult to quantify (Guzzetti, 2000, 2006; Guzzetti et al., 2005b). In the catalogue, lack of occurrences in any given period may be due either to the catalogue's incompleteness or to variation in the conditions that led to slope failures and inundations, including climate anomalies, rainfall events, earthquakes, land-use changes, and human actions.

An approach to evaluate the completeness of an historical catalogue consists in the analysis of the cumulative number of occurrences, which is easily obtained by adding progressively the number of occurrences recorded in a time interval (e.g., a day, a year) (Guzzetti, 2000, 2006). Figure 1 shows the cumulative number of casualties per year, for the 1166-year period 843-2008 for landslides (Fig. 1a), for the 1338-year period 671-2008 for floods (Fig. 1e), and for the 159-year period between 1850 and 2008 for both landslides (Fig. 1b) and floods (Fig. 1f). Inspection of the cumulative plots (dashed lines) reveals changing trends in the total number of casualties, which increases with time. Examination of the plots showing the number of landslide (Fig. 1c, d) and flood (Fig. 1g, h) casualties per event indicates that the increase in the reported number of casualties depends on the intensity of the event. In the early period of the catalogue (i.e., before 1850), events causing a single casualty or a few casualties are rare, compared to the number of events that resulted in several casualties. Even considering the increase in population that has occurred in Italy in the considered period, there is no reason for the distribution of less catastrophic events to be so skewed, except for incompleteness in the catalogue. 


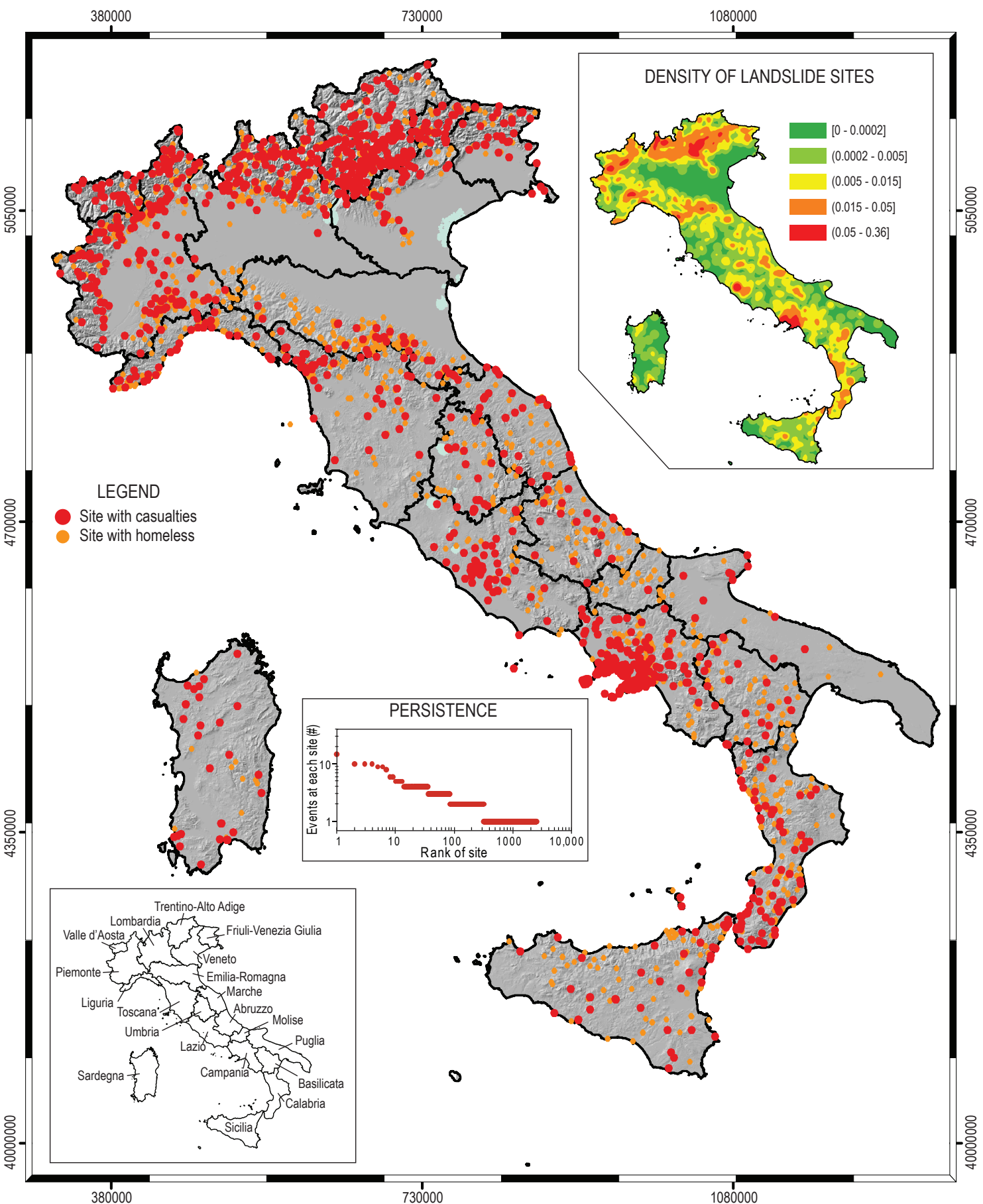

Fig. 2. Map showing the location of 2533 sites affected by landslide events with direct consequences to the population of Italy, in the 1359 year period 650-2008. Map in the upper-right corner shows density of landslide sites per square kilometre, in five classes. Plot in the central inset shows number of landslide events at each site (y-axis) against rank (x-axis), in logarithmic coordinates. Map in the lower-left corner shows location of the 20 Italian Regions.

\subsection{Geographical analysis}

Information on the precise or approximate location of landslides and floods with direct human consequences is available for most of the events in the historical catalogue (95\%).
Figure 2 shows the location of 2533 sites that suffered one or more landslide event in the period $650-2008$, and Fig. 3 shows the location of 1836 sites that suffered one or more flood event with human consequences in the period 


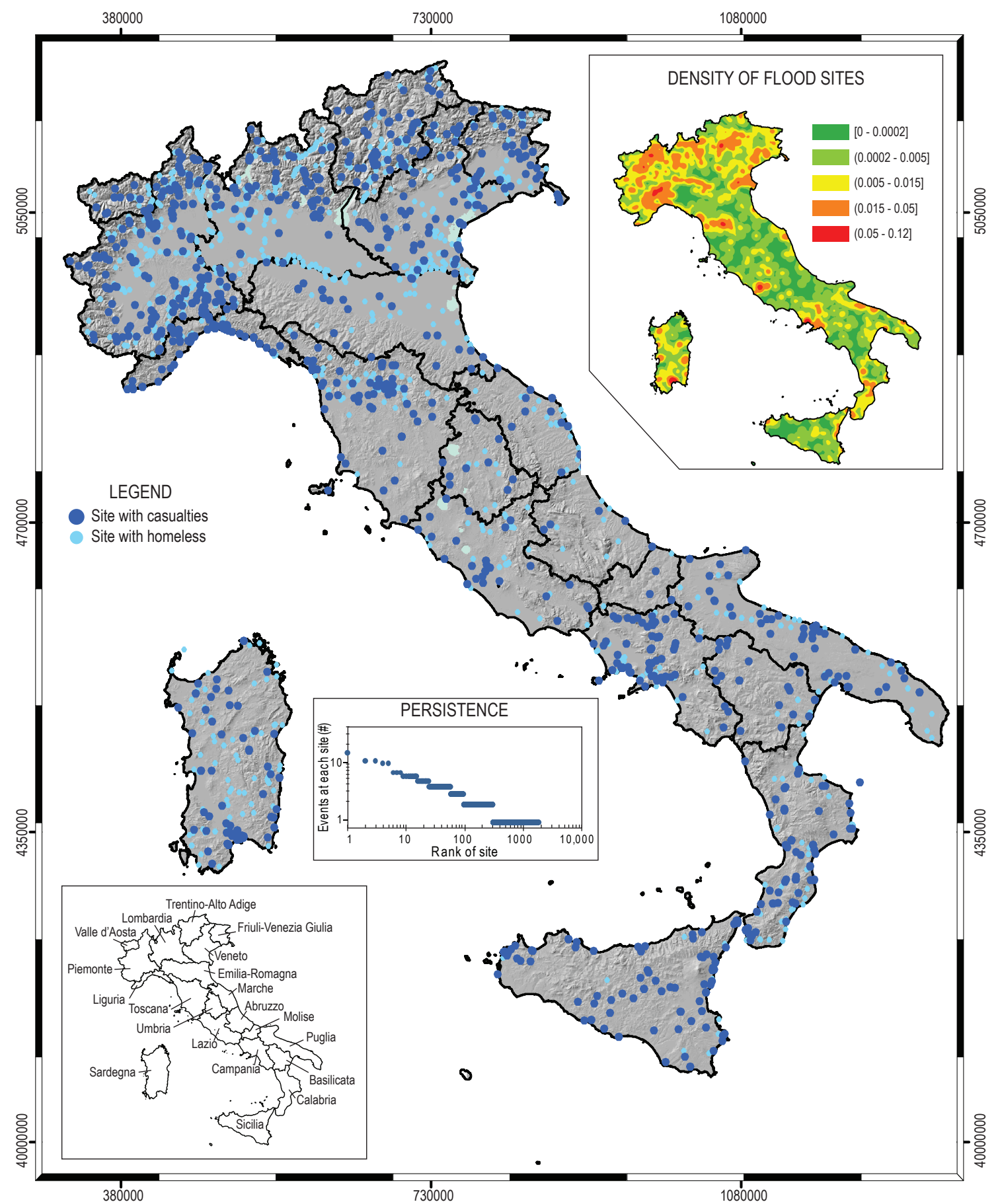

Fig. 3. Map showing the location of 1836 sites affected by flood events with direct consequences to the population of Italy, in the 1419 -year period 590-2008. Map in the upper-right corner shows density of flood sites per square kilometre, in five classes. Plot in the central inset shows number of flood events at each site (y-axis) against rank (x-axis), in logarithmic coordinates. Map in the lower-left corner shows location of the 20 Italian Regions.

590-2008. Sites affected by harmful events were mapped at $1: 25000$ or $1: 100000$ scale, using topographic base maps prepared by the Italian National Geographical Institute. Harmful events occurred in all the 20 Italian Regions, and in 2496 of the 8102 Italian municipalities (31\%), with 1378 municipalities (17\%) that experienced fatal events, and 1428 municipalities (18\%) that experienced events with casualties. 
Table 2. Number of landslide and flood events with casualties, and number and density of landslide and flood casualties in three main geographical areas in Italy, for four periods.

\begin{tabular}{|c|c|c|c|c|c|c|c|c|c|c|c|c|c|}
\hline & \multirow{3}{*}{$\begin{array}{c}\text { Area } \\
\%\end{array}$} & \multicolumn{3}{|c|}{$1850-2008$} & \multicolumn{3}{|c|}{$1850-1899$} & \multicolumn{3}{|c|}{ 1900-1949 } & \multicolumn{3}{|c|}{$1950-2008$} \\
\hline & & \multirow{2}{*}{$\begin{array}{c}\text { Events } \\
\quad \#\end{array}$} & \multicolumn{2}{|c|}{ Casualties } & \multirow{2}{*}{$\begin{array}{c}\text { Events } \\
\#\end{array}$} & \multicolumn{2}{|c|}{ Casualties } & \multirow{2}{*}{$\begin{array}{c}\text { Events } \\
\quad \#\end{array}$} & \multicolumn{2}{|c|}{ Casualties } & \multirow{2}{*}{$\begin{array}{c}\text { Events } \\
\quad \#\end{array}$} & \multicolumn{2}{|c|}{ Casualties } \\
\hline & & & $\#$ & $\# / 10^{3} \mathrm{~km}^{2}$ & & \# & $\# / 10^{3} \mathrm{~km}^{2}$ & & \# & $\# / 10^{3} \mathrm{~km}^{2}$ & & $\#$ & $\# / 10^{3} \mathrm{~km}^{2}$ \\
\hline \multicolumn{14}{|c|}{ Landslides } \\
\hline North & 39.9 & 714 & 4667 & 38.7 & 64 & 446 & 3.7 & 196 & 607 & 5.0 & 454 & 3614 & 30 \\
\hline Central & 22.9 & 189 & 631 & 9.1 & 4 & 13 & 0.2 & 41 & 208 & 3.0 & 144 & 410 & 5.9 \\
\hline South & 37.2 & 500 & 3100 & 27.5 & 14 & 204 & 1.8 & 122 & 798 & 7.1 & 364 & 2098 & 18.6 \\
\hline \multicolumn{14}{|l|}{ Floods } \\
\hline North & 39.9 & 488 & 1934 & 16.0 & 67 & 303 & 2.5 & 159 & 924 & 7.6 & 262 & 707 & 5.9 \\
\hline Central & 22.9 & 123 & 752 & 10.9 & 4 & 8 & 0.1 & 27 & 64 & 0.9 & 92 & 680 & 9.8 \\
\hline South & 37.2 & 418 & 2783 & 24.7 & 24 & 373 & 3.3 & 141 & 1117 & 9.9 & 253 & 1293 & 11.5 \\
\hline
\end{tabular}

Inspection of the historical catalogue suggests that landslide and flood events affected many sites repeatedly, but relatively few sites were damaged very frequently (Salvati et al., 2003; Guzzetti et al., 2005b). To quantify this behaviour, we: (i) counted the number of events at each site, (ii) ordered (ranked) the sites on the total number of events at each site, from largest (several events) to smallest (one event), and (iii) plotted the number of events at each site (y-axis) against their rank (x-axis), in logarithmic coordinates. Results are shown in the central insets of Fig. 2 for landslides and Fig. 3 for floods. Of the 2533 landslide sites, 314 (12.4\%) were affected two times or more, $11(0.4 \%)$ were affected five times or more, and only four sites $(0.2 \%)$ were affected ten times or more. Similarly, of the 1836 flood sites, 301 (16.4\%) were affected two or more times, $22(1.2 \%)$ were affected five or more times, and only three sites $(0.2 \%)$ were affected ten or more times. We conclude that landslide and flood risk is widespread in Italy, but the sites where severely harmful events are very frequent are few. At these sites, landslide and flood risk is high and persistent, because the average interval between damaging events is short.

Guzzetti et al. (1994) examined an early version of the AVI (an Italian acronym for Aree Vulnerate Italiane, Areas Affected by Landslides and Floods in Italy) project catalogue of historical landslides and floods in Italy, and established that the spatial persistence (i.e., the occurrence of multiple events at the same site) of historical floods was significantly larger than the persistence of landslides. Salvati et al. (2006), working in the Umbria Region, central Italy, confirmed the different behaviour of landslide (less persistent) and flood (more persistent) events. Our analysis of the catalogue of landslide and flood events with direct consequences to the population of Italy indicates that the spatial persistence of floods and landslides are similar (upper-right inset in Fig. 2). We attribute the discrepancy to differences in the information content of the two types of sources. The AVI catalogue and the catalogue of historical landslide and flood events in Umbria include all types of damaging events, and not only the events that have caused direct damage to the population. Our new catalogue for Italy contains only landslide and flood events that have resulted in direct damage to the population. In addition, when a site is affected by a harmful landslide or flood event, the local population recognizes the area as dangerous, and defensive measures are adopted or the area is abandoned. This reduces the likelihood of multiple harmful events at the same site.

Visual inspection of Figs. 2 and 3 reveals that sites affected by harmful landslides and floods are not distributed equally in Italy. In the catalogue, harmful landslides are most abundant in the Alps, in southern Piedmont Region, and in the Campania and Calabria Regions, southern Italy (upper-right inset in Fig. 2), and harmful floods are most common in the western Alps, in the large flood plains of northern Italy, in Tuscany and in Campania Regions, and locally along the coasts (upper-right inset in Fig. 3).

Table 2 lists the number of landslide and flood events with casualties, and the number of landslide and flood casualties in three broad geographical areas in Italy, for four periods. The geographical areas include: (i) northern Italy $\left(120 \times 10^{3} \mathrm{~km}^{2}\right)$, encompassing the Italian Alps, the Po and Veneto plains, and part of the northern Apennines, (ii) central Italy $\left(69 \times 10^{3} \mathrm{~km}^{2}\right)$, comprising the central Apennines, the northern and central Tyrrhenian coast, and the central Adriatic coast, and (iii) southern Italy $\left(112 \times 10^{3} \mathrm{~km}^{2}\right)$, that consists of the southern Apennines, the southern Tyrrhenian coast, the southern Adriatic coast, the Ionian coast, Sicily and Sardinia. To account for the different extent of the three geographical areas, Table 2 also lists the density of landslide and flood casualties per unit area (i.e., per $10^{3} \mathrm{~km}^{2}$ ).

In the period 1850-2008, the largest number of landslide (714) and flood (488) events with casualties occurred in northern Italy. In this period, landslide casualties were most abundant in northern Italy (4667) followed by southern Italy (3100), and flood casualties were most numerous in southern Italy (2783) followed by northern Italy (1934). 


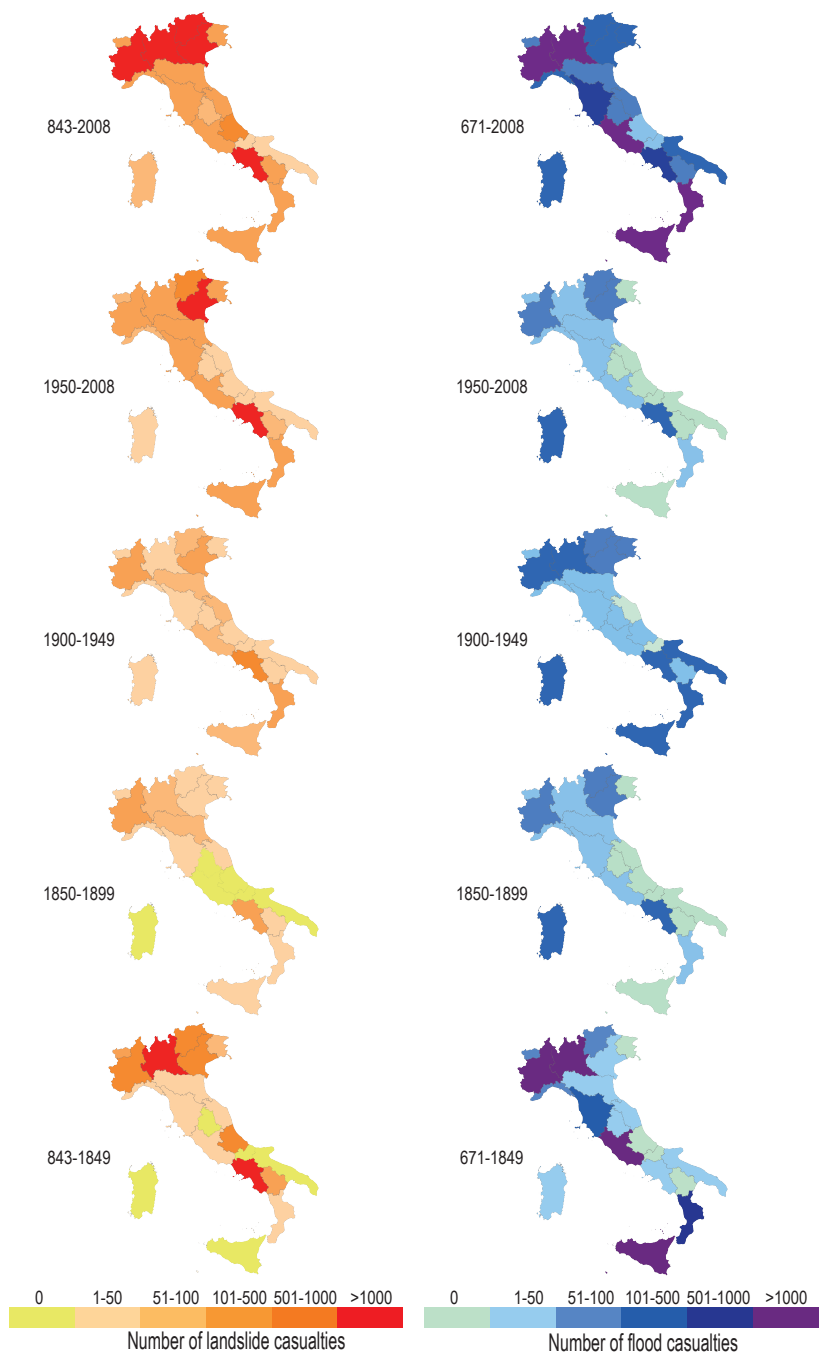

Fig. 4. Maps of Italy showing the total number of landslide (shades of red) and flood (shades of blue) casualties in the 20 Italian Regions, for five periods.

From 1850 to 2008 , the density of landslide casualties was largest in northern Italy $\left(38.7\right.$ casualties per $10^{3} \mathrm{~km}^{2}$ ), followed by southern Italy $\left(27.5\right.$ casualties per $10^{3} \mathrm{~km}^{2}$ ), and least in central Italy $\left(9.1\right.$ casualties per $\left.10^{3} \mathrm{~km}^{2}\right)$. In the same period, the density of flood casualties was largest in southern Italy $\left(24.7\right.$ casualties per $\left.10^{3} \mathrm{~km}^{2}\right)$, followed by northern Italy $\left(16.0\right.$ casualties per $\left.10^{3} \mathrm{~km}^{2}\right)$, and least in central Italy $\left(10.9\right.$ casualties per $\left.10^{3} \mathrm{~km}^{2}\right)$. Inspection of Table 2 reveals that the relative abundance of landslide events with casualties, and of the total number of landslide casualties in the three considered geographical regions does not change significantly in the most recent part of the catalogue (1950-2008). In this period, the density of flood casualties was largest in southern Italy, followed by central Italy (9.8 casualties per $10^{3} \mathrm{~km}^{2}$ ).
Figure 4 shows the total number of landslide and flood casualties in the 20 Italian Regions, for different periods. Inspection of Fig. 4 allows for further considerations on the regional distribution of landslide and flood casualties in Italy. From 1850 to 2008 , the Region that has experienced the largest number of landslide casualties (2164, in 321 events) is the Campania Region, southern Italy. Campania is also the second Region in terms of the total number of landslide casualties in the most recent period of the catalogue (1950 2008), preceded by the Veneto Region, northern Italy, with 1877 casualties, most of which caused by the 9 October 1963 Vajont rockslide. The large number of landslide casualties in Campania is due mostly to soil slips and debris flows in areas where a cover of volcanic ash overlies limestone on steep slopes, a highly hazardous geological setting typical of the area surrounding the Vesuvius volcano (Guzzetti et al., 2005b).

Considering the entire span of the flood catalogue (5892008), Sicily experienced the largest number of flood casualties, due largely to the September 1557 event in the Palermo area that resulted in 7000 casualties. In the catalogue, the single most destructive flooding event occurred along the Po River in 1705. For this event, the total number of casualties remains uncertain, but up to 15000 people were killed, went missing, or were injured at multiple sites by extensive flooding. For the event, the historical information available to us was insufficient to locate the human consequences precisely, or even approximately. In the period 1850-2008, the Piedmont Region, northern Italy, experienced the largest number of flood events with casualties (149), whereas the largest number of flood casualties (660) was reported in Calabria, southern Italy.

The large density of landslide casualties in northern Italy is due to the meteorological, morphological, and geological settings. In northern Italy high intensity and prolonged rainfall events, combined with the availability of debris on steep slopes, make destructive debris flows common. The presence of high relative relief and the cropping out of hard rocks, such as granite, metamorphic rocks, massive limestone and dolomite, facilitate rock falls, rock slides, and rock avalanches (Guzzetti, 2000). These types of landslides are particularly hazardous because of their high velocity. Northern Italy includes the Po and the Adige river basins, the first and the third largest basins in Italy, where landslides are abundant and floods are frequent.

In southern Italy the combination of climatic, meteorological, geological and morphological conditions are particularly favourable to the occurrence of harmful events. Landslide casualties are most abundant in Campania, Calabria, Basilicata, and Sicily, and flood casualties are most numerous in Calabria, Sicily, and Campania. In these areas, slopes are steep, relative relief is high, catchments are small, and rocks are highly stressed and easily erodible (Esposito et al., 2002, 2003; Porfido et al., 2009). When high-intensity, shortduration convective storms strike these areas, they produce 
highly destructive flash floods and they trigger large clusters of mostly shallow landslides. The 1 October 2009 high intensity rainstorm in the Messina area, Sicily, gave an example of the destructiveness of such events. In less than $12 \mathrm{~h}$, in an area of about $60 \mathrm{~km}^{2}$, high intensity rainfall (exceeding $230 \mathrm{~mm}$ in eight hours) caused more than 500 landslides (mainly soil slides and debris flows), widespread inundation associated with massive erosion and deposition of debris along the drainage network, and modification of the coast line that locally was moved several tens of meters seaward. Landslides and inundation caused 31 deaths, 6 missing persons, and an undetermined number of injured people. The evacuees and the homeless people exceeded 2500.

\section{Risk evaluation}

To ascertain the societal (collective) risk posed by landslides and floods in Italy, and in each of the 20 Italian Regions, we exploited the new catalogue of landslide and flood events that have resulted in casualties (deaths, missing persons, and injured people). To limit problems related to the incompleteness of the catalogue for the early periods, we used only the recent portion of the catalogue covering the 159 -year period from 1850 to 2008 .

We started by ordering (ranking) the harmful events listed in the catalogue, for the whole of Italy and for the 20 individual Regions, on their intensity (the number of casualties), from smallest to largest events. Next, we plotted the number of casualties per event against their rank (i.e., the order in the catalogue), from smallest (low intensity) to largest (high intensity) events. Results are shown in Fig. 5 for landslides and Fig. 6 for floods, for the 159-year period 1850-2008 (open symbols) and for the 59-year period 1950-2008 (filled symbols). Inspection of the log-log plots reveals that the relationship to link the intensity of the event (y-axis) to its rank (x-axis) is generally linear, and can be approximated by a power law. The power law trend holds in the range between 1 and about 20 casualties for the individual Regions, and between 1 and about 30 casualties for the entire Italian territory. This is in an agreement with previous findings by Guzzetti et al. (2005b).

Comparison of the individual plots in Figs. 5 and 6 reveals significant differences, which are indicative of different societal risk levels in the various Italian Regions. To quantify the differences, and obtain quantitative estimates for societal landslide and flood risk, we prepared a model for the probability of the harmful events. When empirical data appear to be power-law distributed, i.e., when they follow a linear trend in log-log coordinates, the Pareto, Zeta, and Zipf distributions can be used to model the data (Reed, 2001; Guzzetti et al., 2005b; Newman, 2005; Rossi et al., 2010). The Pareto distribution prescribes a power-law probability for the size of a random event, given that the size can take any fractional value (real number) above a given minimum value. The Zeta and the Zipf distributions are similar, and prescribe a powerlaw probability for the size of a random event that takes an integer value of at least one (natural number) (Reed, 2001; Newman, 2005; Rossi et al., 2010). Although the terms "Zeta distribution" and "Zipf distribution" are often used interchangeably, a difference exists between the two distributions. The Zeta distribution is defined for a population of infinite size, whereas the Zipf distribution is defined for a population of finite size (Newman, 2005). Since the number of landslide and flood casualties is discrete (a landslide or flood can cause e.g., 1, 2, and 10 casualties, but not e.g., 1.5, 2.4 , or 10.3 casualties), and because the maximum number of casualties in an event is finite (Table 1), the Zipf distribution is best suited to describe the probability of a landslide or flood event with a given number of casualties.

For a Zipf distribution, the probability mass function, PMF (equivalent to the probability density function, pdf, for discrete data), is given by:

$\operatorname{PMF}(c ; s, N)=\frac{1}{c^{s} H_{N, s}}$

Where $c$ is the number of casualties per event, $s$ is the distribution parameter (the scaling exponent for the Zipf distribution that measures the proportion of small versus large events), and $N$ is the largest number of casualties in a single event in the analyzed dataset, and

$H_{N, s}=\sum_{c=1}^{N} \frac{1}{c^{s}}$,

with

$s \in \mathbb{R}^{+} ; c \in\{1,2, \ldots, N\}$

We used maximum likelihood estimation, MLE (Fisher, 1922a, b; White et al., 2008) - a parametric method that requires the selection of a probability distribution to model the data - to determine the PMF for landslide and flood events with casualties in Italy, and in the 20 individual Regions. To investigate possible variations of societal risk with time, the analysis was performed for three overlapping periods: (i) the 159-year period 1850-2008, (ii) the 109-year period 1900-2008, and (iii) the 59-year period 1950-2008. Figures 7, 8, and 9 summarize the results, for landslides (red lines) and floods (blue lines). To evaluate the performance of the Zipf models, we prepared Q-Q (quantile-quantile) plots (Wilk and Gnanadesikan, 1968), shown as insets in the individual plots in Figs. 7, 8, and 9, and we performed 2-sample Kolmogorov-Smirnov tests (Kolmogorov, 1933; Smirnov, 1933) (Tables 3 and 4). In the tests, lower values of the $k s$ statistic, and larger values of the p-value, indicate a better model fit (Rossi et al., 2010). For a few Regions (Molise for landslides, and Abruzzo, Molise, and Valle d'Aosta for floods), the number of harmful events in the catalogue was insufficient to determine the PMF of the casualties through MLE. 

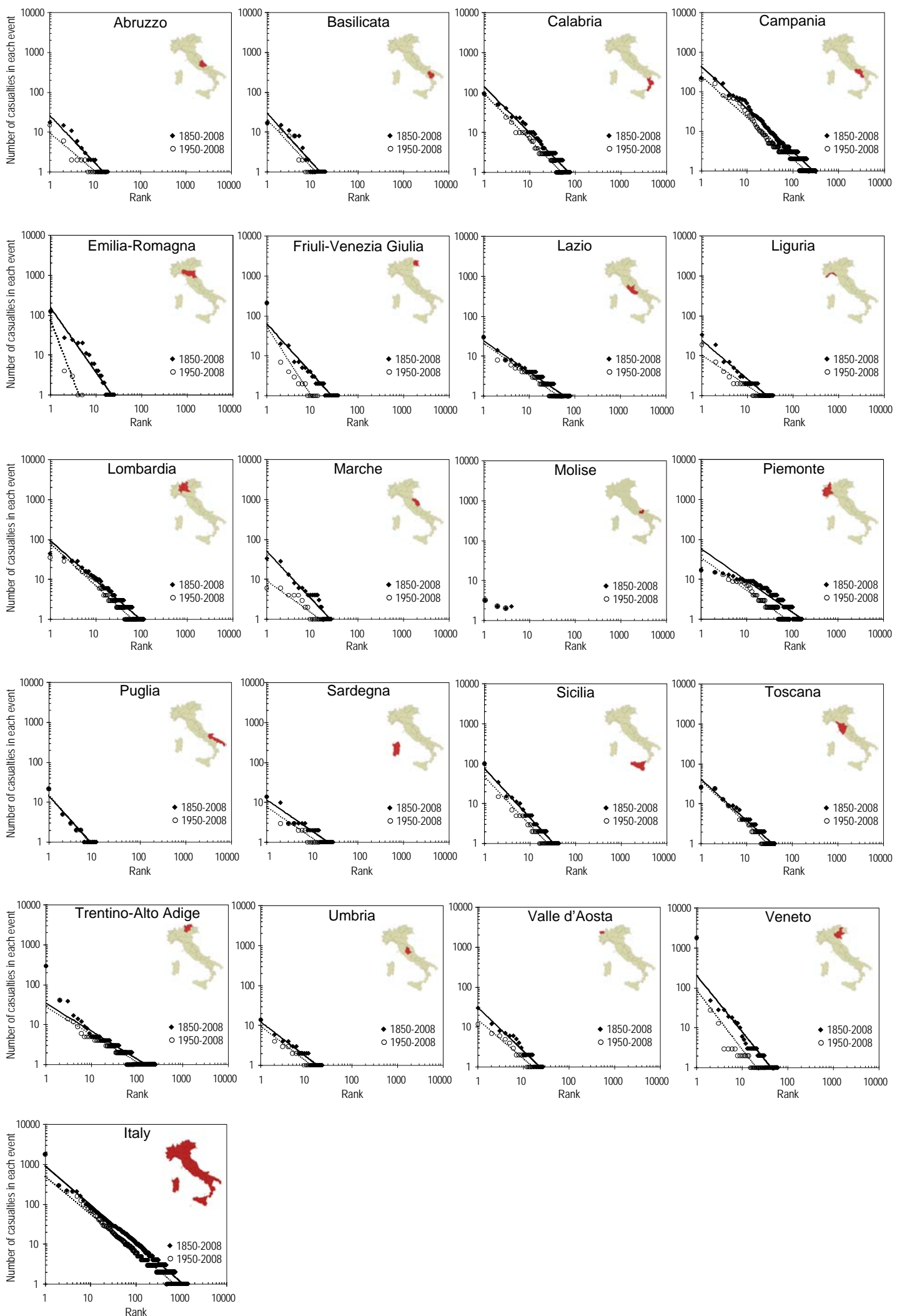

Fig. 5. Plots showing the intensity of the landslide events (y-axis), measured by the number of casualties in each event, versus the rank (x-axis), for the individual Italian Regions (location of the Region in Italy shown by small maps), and for Italy (lower right plot). Filled symbols for 159-year period 1850-2008, open symbols for 59-year period 1950-2008. Dashed and continuous lines are best fit lines (least square method) to open and filled symbols, respectively. 

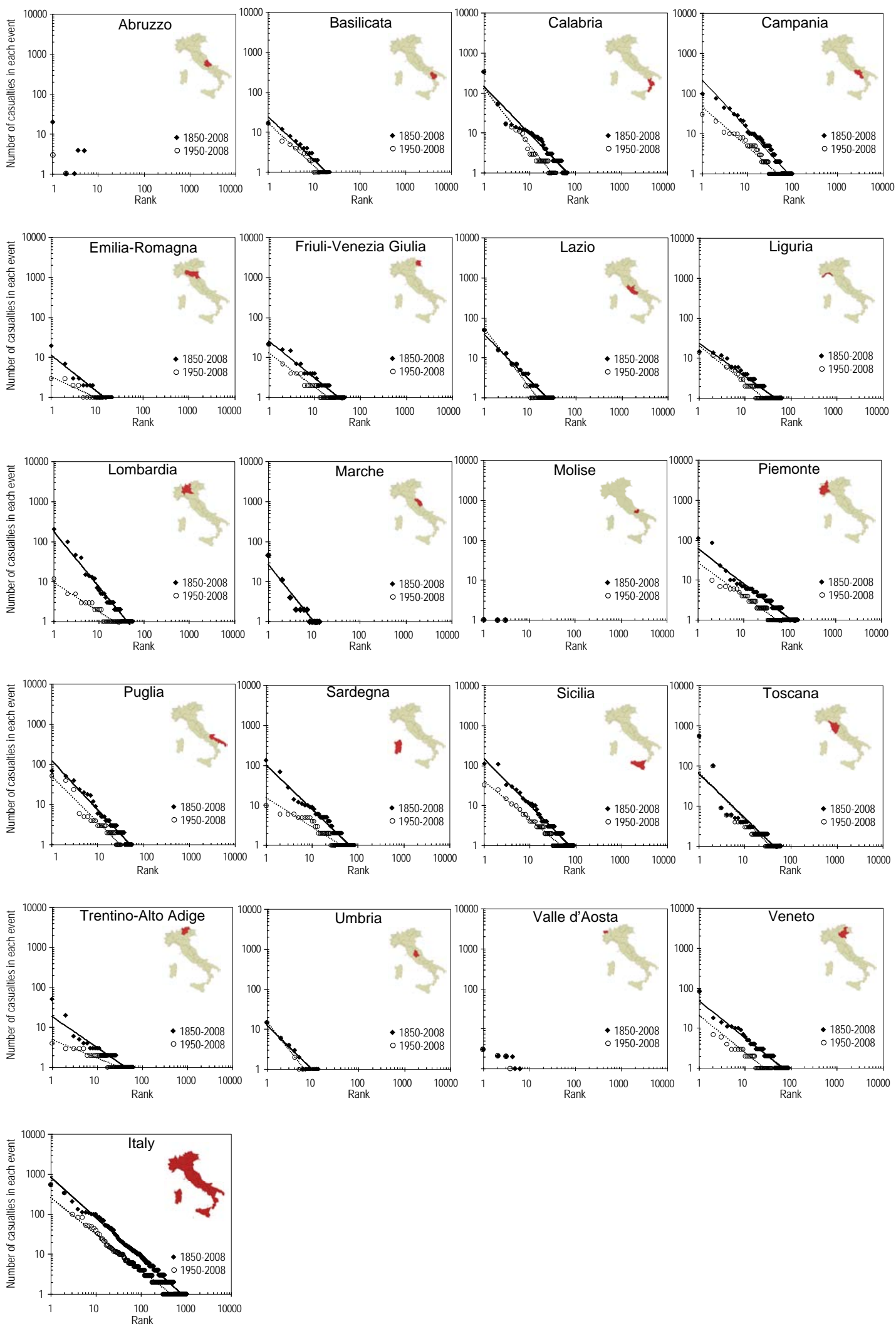

Fig. 6. Plots showing the intensity of the flood events (y-axis), measured by the number of casualties in each event, versus the rank (x-axis), for the individual Italian Regions (location of the Region in Italy shown by small maps), and for Italy (lower right plot). Filled symbols for 159-year period 1850-2008, open symbols for 59-year period 1950-2008. Dashed and continuous lines are best fit lines (least square method) to open and filled symbols, respectively. 

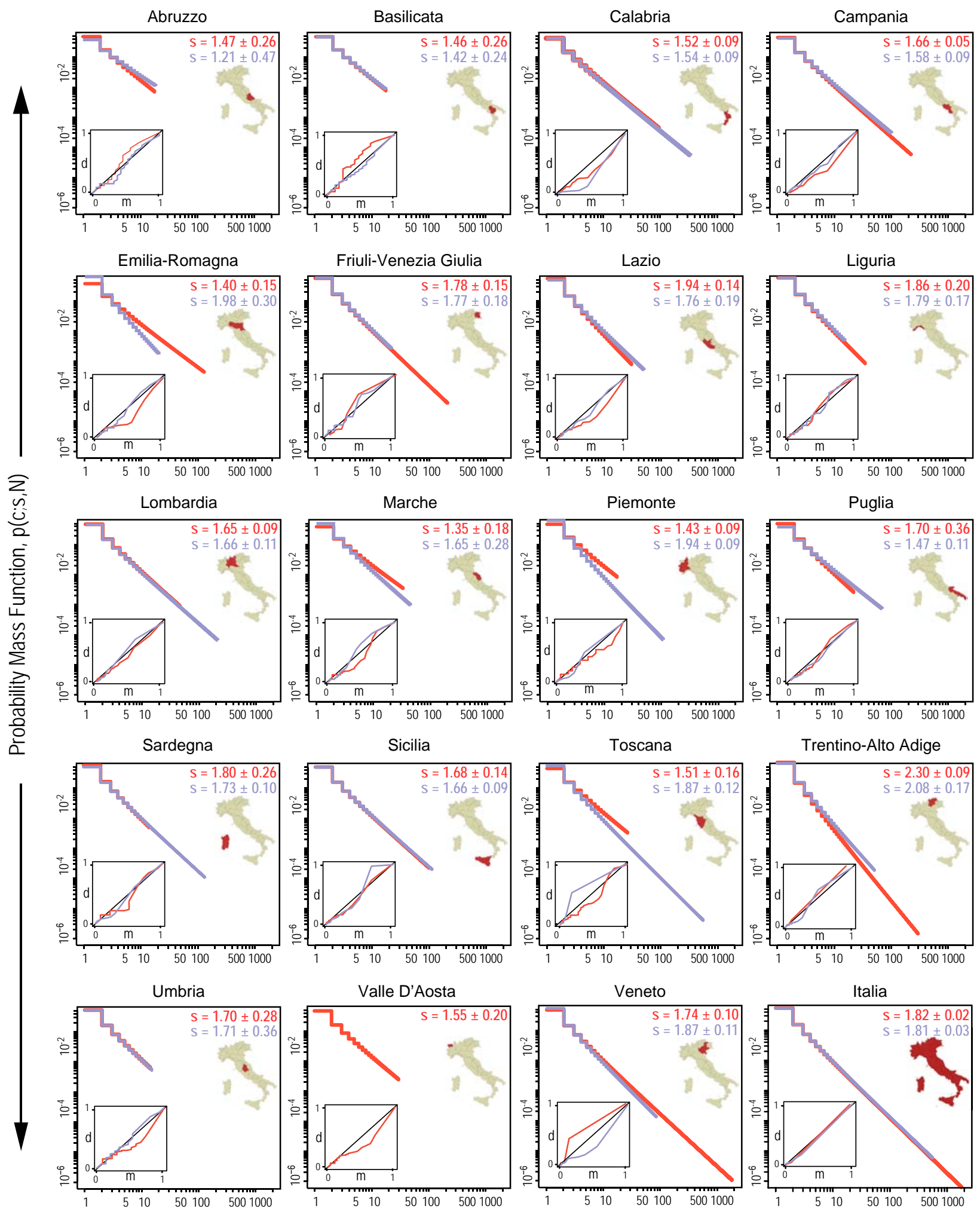

Number of Casualties, (c)

Fig. 7. For the 159-year period 1850-2008, the plots show the Probability Mass Function (PMF) of landslide (red) and flood (blue) events with casualties, for the individual Italian Regions (location of the Region in Italy shown by small maps), and for Italy (lower right plot). The $s$ parameter is the scaling exponent of the Zipf distribution used to model the empirical data. Insets show normalized Q-Q plots; $\mathrm{m}=$ model, $\mathrm{d}=$ empirical data. Molise Region for landslides and floods, and Valle d'Aosta Region for floods are not shown due to the lack of data. 


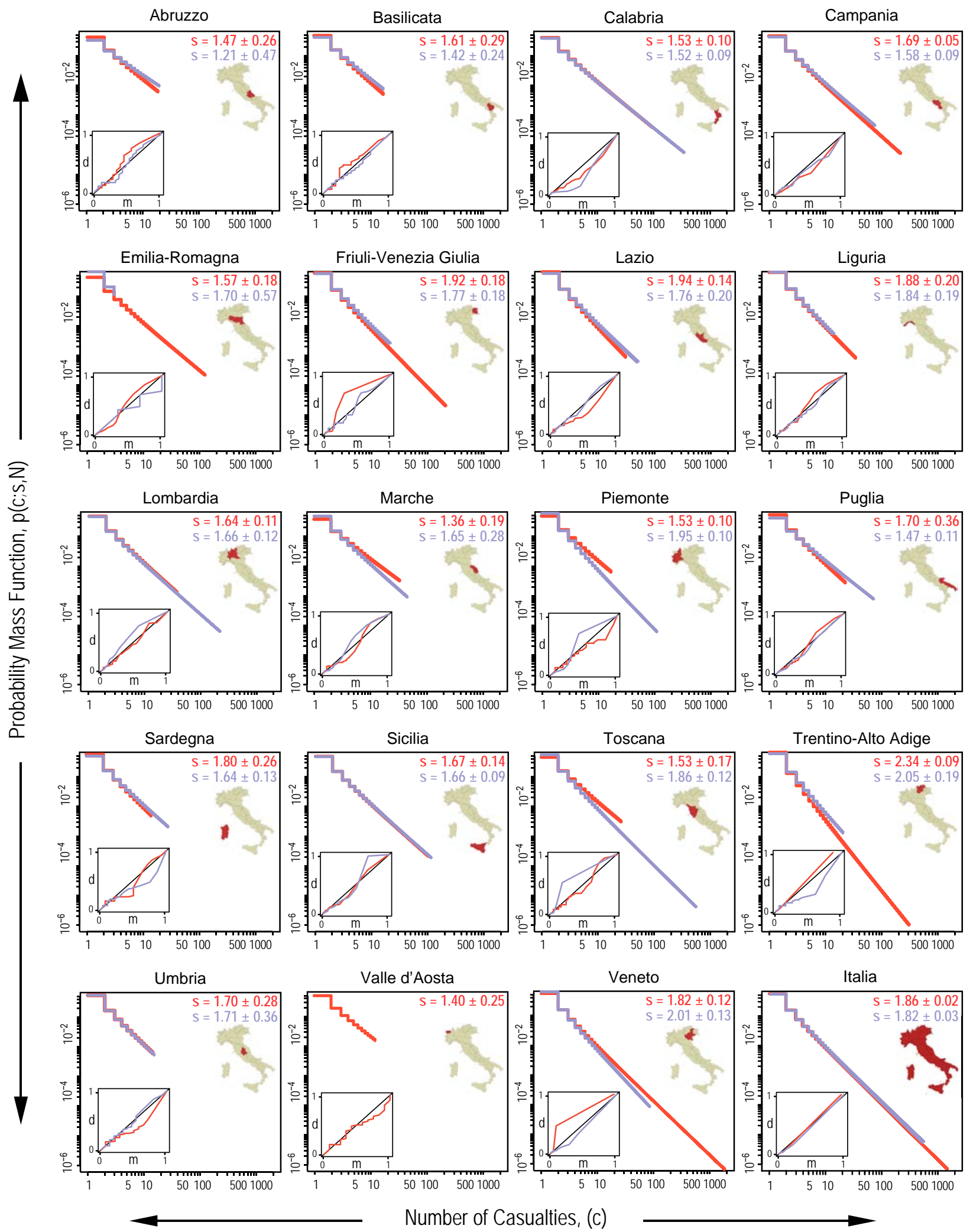

Fig. 8. For the 109-year period 1900-2008, the plots show the Probability Mass Function (PMF) of landslide (red) and flood (blue) events with casualties, for the individual Italian Regions (location of the Region in Italy shown by small maps), and for Italy (lower right plot). The $s$ parameter is the scaling exponent of the Zipf distribution used to model the empirical data. Insets show normalized Q-Q plots; $\mathrm{m}=$ model, $\mathrm{d}=$ empirical data. Molise Region for landslides and floods, and Valle d'Aosta Region for floods are not shown due to the lack of data. 

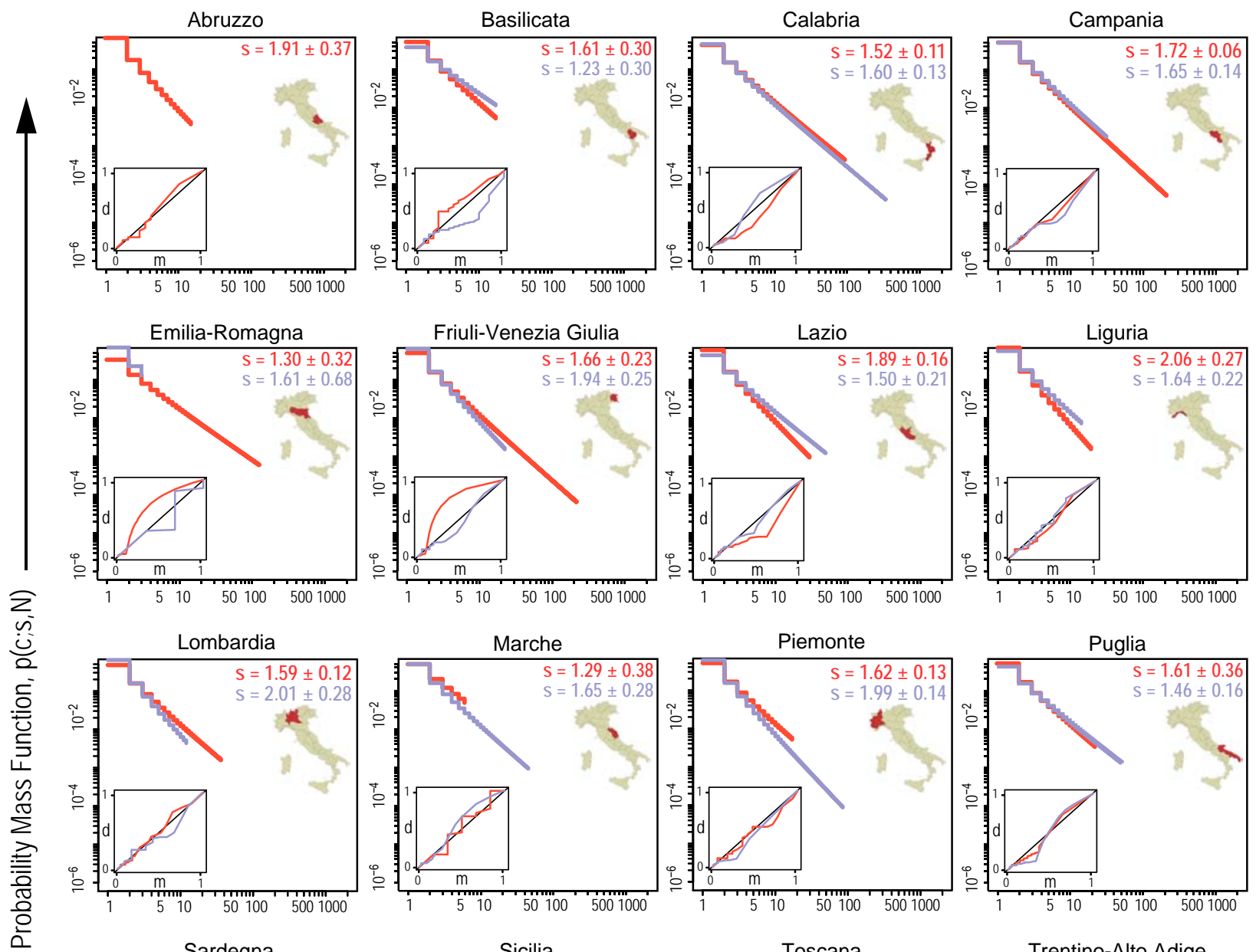

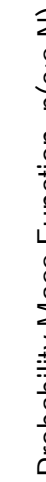
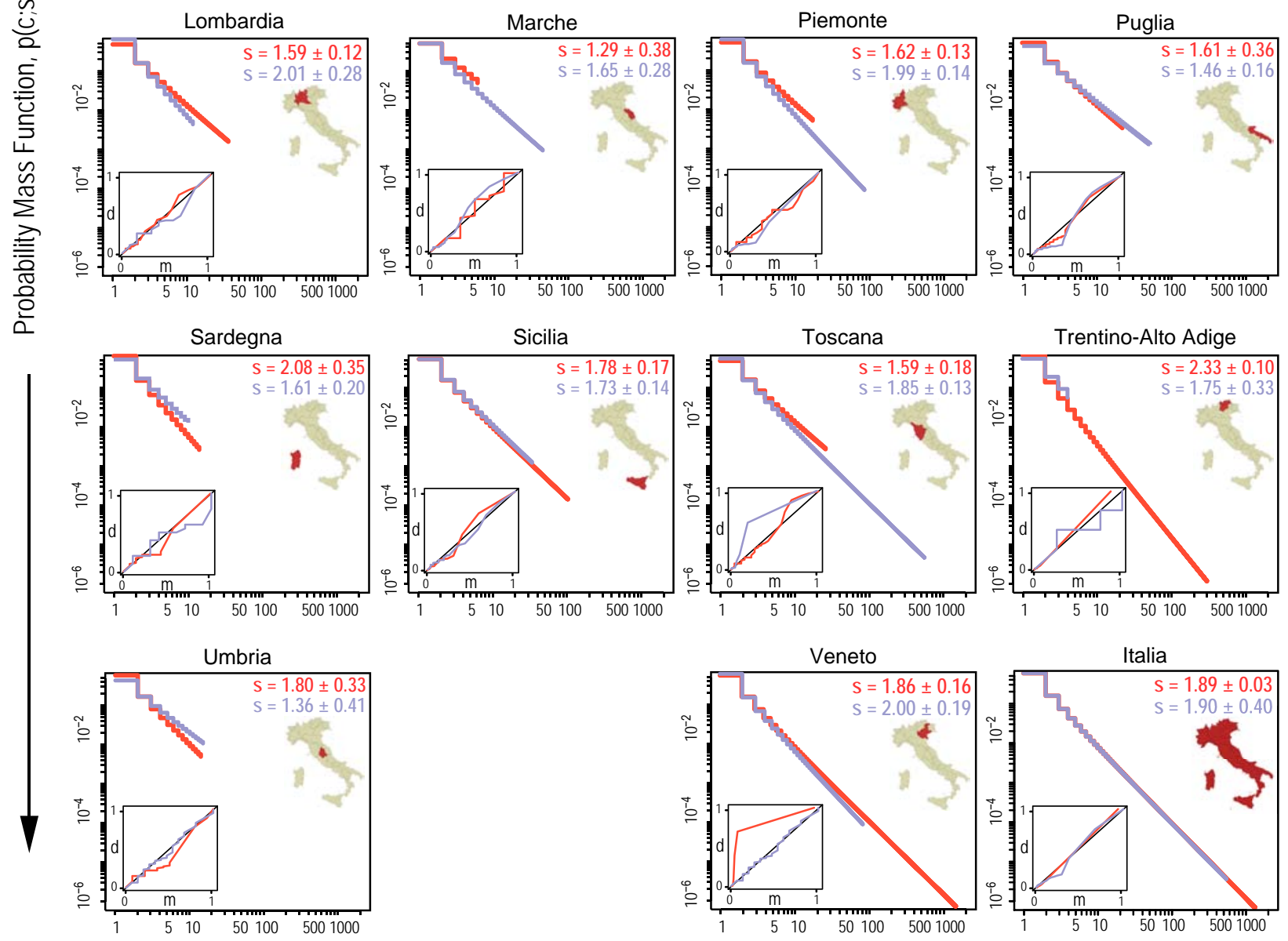

Number of Casualties, (c)

Fig. 9. For the 59-year period 1950-2008, the plots show the Probability Mass Function (PMF) of landslide (red) and flood (blue) events with casualties, for the individual Italian Regions (location of the Region in Italy shown by small maps), and for Italy (lower right plot). The $s$ parameter is the scaling exponent of the Zipf distribution used to model the empirical data. Insets show normalized Q-Q plots; $\mathrm{m}=$ model, $\mathrm{d}=$ empirical data. Molise and Valle d'Aosta Regions for landslides and floods, and Abruzzo for floods are not shown due to the lack of data. 


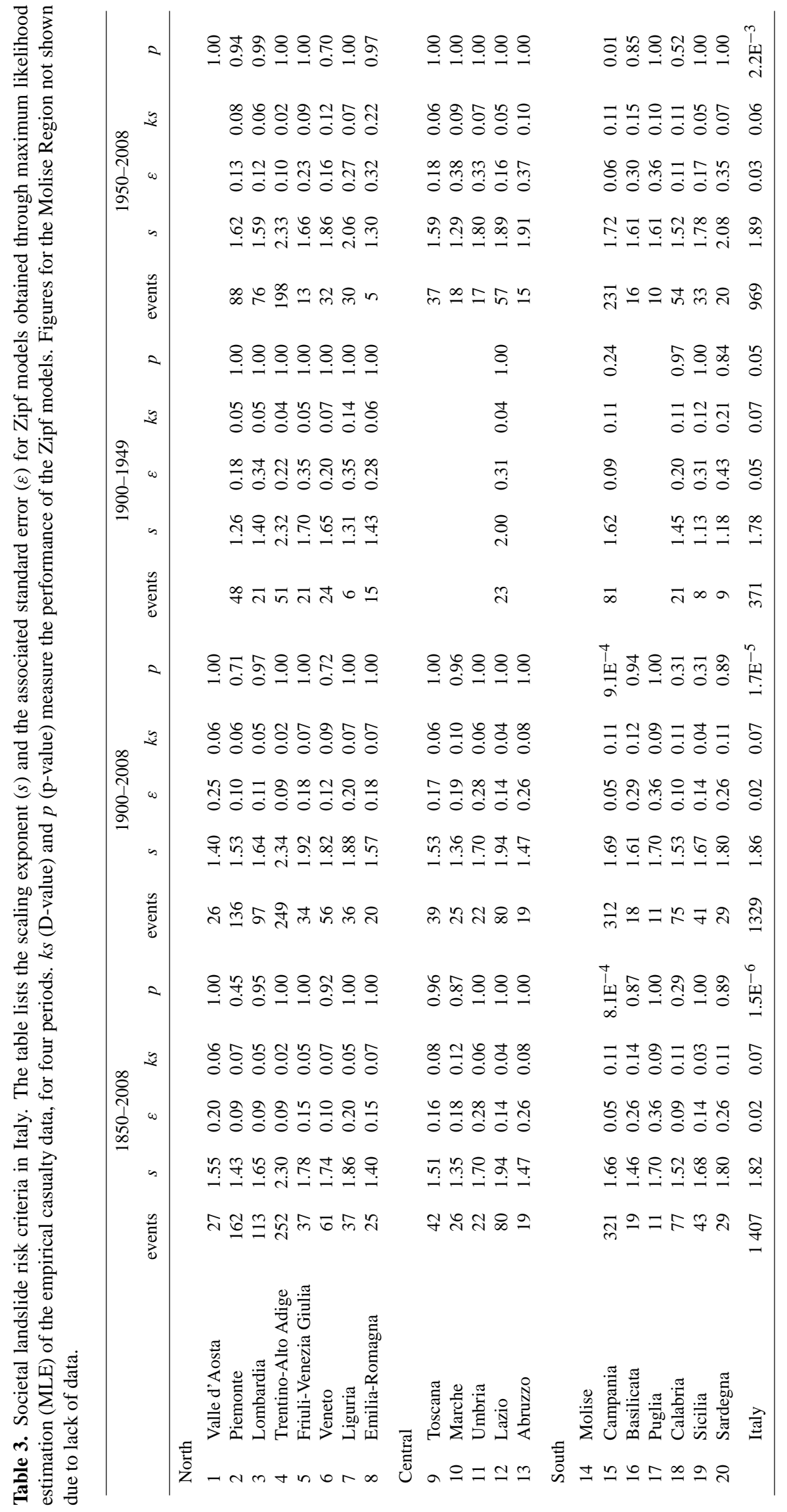




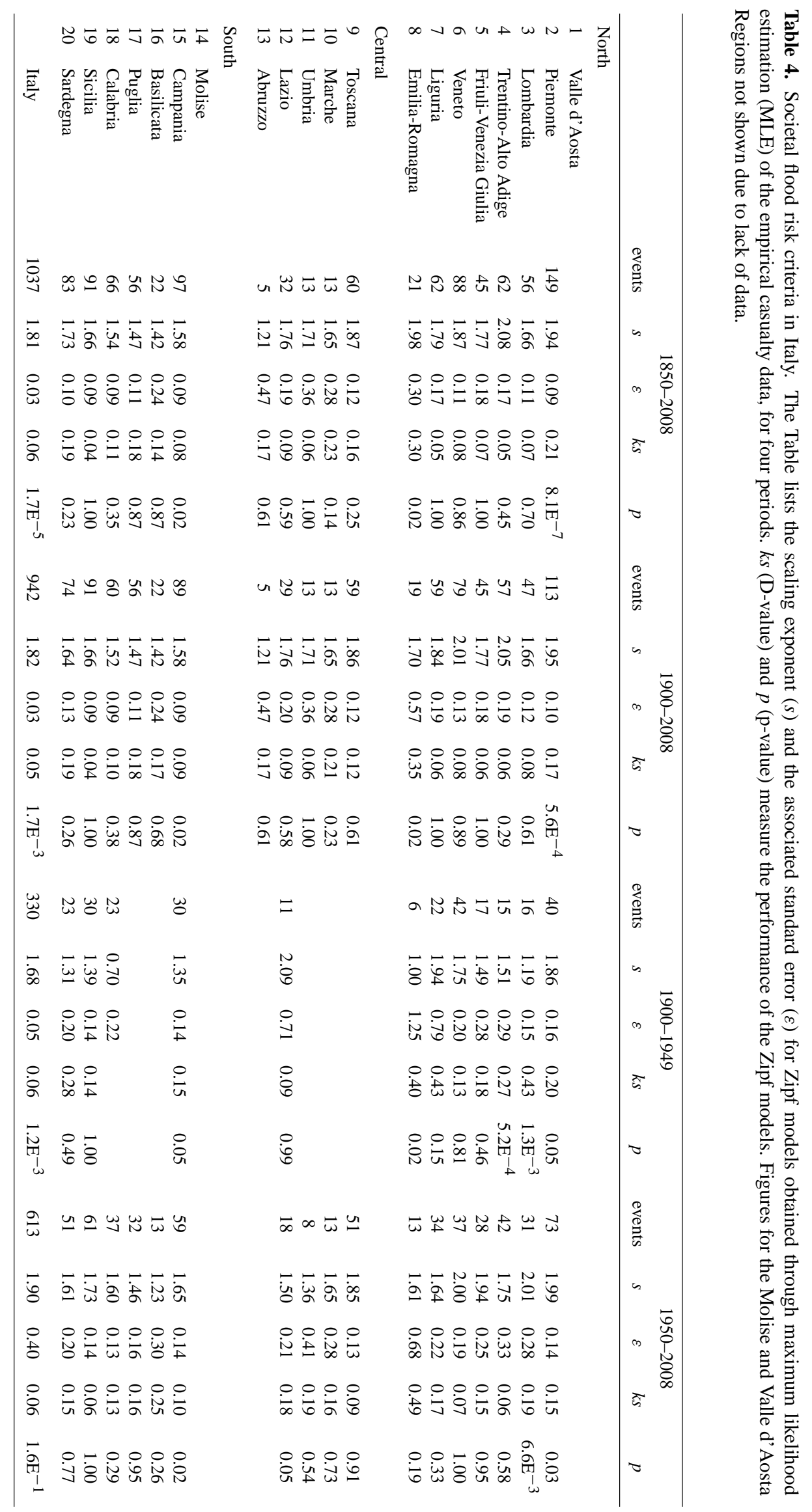




\section{Discussion}

In Figs. 7, 8, and 9, the empirical casualty data for Italy and for the 20 Italian Regions (symbols) are reasonably well described by the Zipf models (lines). We take this as indication that the Zipf distribution is suited to describe casualty (and fatality) data in Italy, and possibly elsewhere.

The Zipf models obtained for Italy, and for the 20 individual Regions, give the expected relative proportion of small, medium and large intensity events, where the total number of casualties in an event measures the intensity. The scaling exponents $s$ for our Zipf models are listed in Table 3 for landslides and in Table 4 for floods, for different periods. Considering the period 1850-2008, the values are, for the entire Italian territory, $s=1.82 \pm 0.02$ for landslides (1407 events), and $s=1.81 \pm 0.03$ for floods ( 1037 events). The values of $s$ increase slightly when the most recent period 1950-2008 is considered: $s=1.89 \pm 0.03$ for landslides (371 events), and $s=1.90 \pm 0.40$ for floods ( 330 events).

The scaling behaviour of the intensity of the casualties found in this work is very similar to what was obtained by Guzzetti et al. (2005b), who used an earlier version of the catalogue of landslides and floods with fatalities in Italy, in the 103-year period 1900-2002. We attribute the observed differences to: (i) the addition of 227 landslide events and 56 flood events with casualties, which has improved the completeness of the catalogue, (ii) the fact that our work was based on the analysis of the casualties (deaths, missing persons, and injured people) whereas Guzzetti et al. (2005b) based their study on the fatalities (deaths and missing persons), and (iii) the different statistical technique used to obtain the PMF of landslide and flood damage.

The scaling exponent (i.e., the slope) $s$ of the modelled Zipf distributions can be used to compare the proportion of events with different intensity in the 20 Italian Regions. Regions exhibiting steep Zipf curves (i.e., having a large scaling exponent $s$ ) have a smaller probability of experiencing large intensity events, when compared to Regions that have less steep curves (i.e., having small exponent $s$ ), for which the relative proportion of large intensity events is larger.

Inspection of Figs. 7, 8, 9, and Tables 3 and 4, reveals that variation exists in the scaling exponents obtained for the 20 Italian Regions. For the period 18502008, $s$ ranges between 1.35 and 2.30 for landslides (mean $\mu=1.66$, standard deviation $\sigma=0.23$ ), and between 1.21 and 2.08 for floods $(\mu=1.71, \sigma=0.21)$. Considering the period 1950-2009, $s$ ranges between 1.29 and 2.33 for landslides $(\mu=1.73, \sigma=0.26)$, and between 1.23 and 2.01 for floods $(\mu=1.68, \sigma=0.23)$. Variations in space (geographically) and time are the results of two main causes: different levels of completeness in the catalogue, geographically and temporally, and differences in societal landslide and flood risk. The latter, depends on: (i) the geological and morphological setting which determine the local susceptibility to harmful landslides and floods, (ii) the frequency and intensity of the triggers (i.e., rainfall, earthquakes, etc.), and (iii) the abundance and distribution of the population at risk.

Analysis of Tables 3 and 4 reveals a temporal and a spatial trend. For most of the Regions for which sufficient information was available to determine the PMF of the casualties, the scaling exponent $s$ of the Zipf distribution increases with time, for both landslides and floods. This indicates that the expected (modelled) proportion of events with a large number of casualties, compared to the proportion of events with fewer casualties, has decreased from 1850 to 2008. This may be the result of a decrease in societal risk, or it may be the result of incompleteness in the catalogue. Although warning systems and remedial measures have been installed in Italy to protect people from landslides and inundations, we attribute the larger values of $s$ primarily to a systematic lack of small intensity events in the early part of the catalogue.

Interpretation of the geographical variation of the $s$ values in Italy is more difficult and uncertain. This is because the regional analysis of societal risk was based on administrative subdivisions (the Regions) that have little relation with the physical (e.g., geological, morphological, hydrological, meteorological) setting, and because the standard error $\varepsilon$ associated with the estimation of $s$ is significant for some of the Regions, a result of the reduced number of events in each Region (Tables 3 and 4). Despite these limitations, a trend emerges from the data. Considering the flood catalogue, and limiting the analysis to the most recent period (1950-2008) that we judge complete for statistical purposes, we find that Regions in northern Italy have larger $s$ values $(\mu=1.85, \sigma=0.18)$ than Regions in central $(\mu=1.59, \sigma=0.21)$ and in southern $(\mu=1.55, \sigma=0.18)$ Italy. This indicates that the probability of experiencing a flood event with a large or very large number of casualties is largest in southern Italy and reduced in northern Italy. A similar, but less distinct, geographical trend exists for landslides. Regions in northern Italy have, on average, slightly larger $s$ values $(\mu=1.77$, $\sigma=0.34)$, than Regions in central $(\mu=1.70, \sigma=0.26)$ and in southern $(\mu=1.72, \sigma=0.20)$ Italy (Tables 3 and 4 ).

Societal landslide and flood risk depends on the relative proportion of small, medium, and large intensity events, which control the slope of the Zipf distribution, and on the temporal frequency of the events, i.e., on the number of events in a period, or per unit time (e.g., a year). In the period 1950-2008, landslide events with casualties were 969, corresponding to 16.4 events per year, and flood events with casualties were 613, corresponding to 10.4 events per year. Figures in Tables 3 and 4 indicate that the number of landslide and flood events with casualties varies in the Italian Regions. Landslide events with casualties ranged from 5 ( 0.1 events per year in Emilia-Romagna) to 231 (3.9 events per year in Campania), and flood events with casualties ranged from 8 (0.1 events per year in Umbria), to 73 (1.2 events per year in Piedmont). 

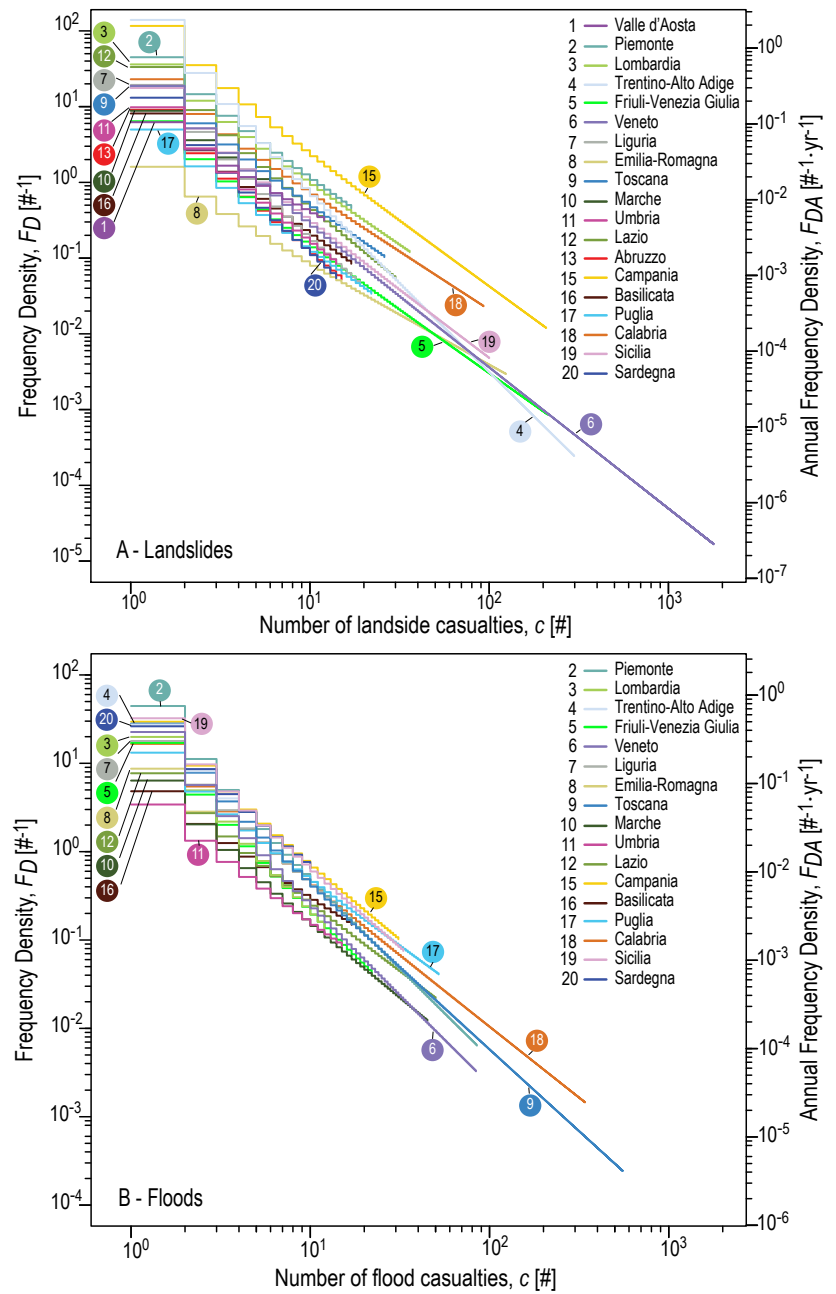

Fig. 10. Plots showing the frequency density (left y-axes) and the annual frequency density (right y-axes) of landslide (upper graph) and flood (lower graph) events with casualties in the Italian Regions against the intensity of the landside and flood events (x-axes), measured by the total number of casualties (deaths, missing persons and injured people), in the 59-year period 1950-2008. Molise and Valle d'Aosta Regions for landslides and floods, and Abruzzo for floods are not shown due to the lack of data.

In an attempt to consider the proportion of events of different intensity and the temporal frequency of the events, for the evaluation and ranking of landslide and flood risk we scaled (i.e., normalized) the PMF obtained for each single Region to the total number of events with casualties in the Region, in the 59-year period 1950-2008 (Fig. 10). Inspection of Fig. 10a reveals that the Trentino-Alto Adige (\# 4) and the Campania (\# 15) Regions exhibit the largest societal landslide risk, and the Emilia-Romagna Region (\# 8) has the lowest landslide risk. For the other Regions, a ranking of societal landslide risk can be obtained based on the location of the frequency curve in the plot, a function of the total number of events with casualties in the catalogue (1950-2008), and on the scaling exponent $s$, a function of the proportion of events of different intensity in the catalogue. Similarly, analysis of Fig. 10b indicates that societal flood risk in Italy is largest in the Piedmont (\# 2) and the Sicily (\# 19) Regions, and lowest in the Umbria (\# 11) and Basilicata (\# 16) Regions, with the other Regions experiencing intermediate levels of societal flood risk.

Inspection of the historical catalogue indicates that the causes for the high landslide risk in the Trentino-Alto Adige Region (northern Italy) and in the Campania Region (southern Italy) are different. In Trentino-Alto Adige Region (\# 4), landslide risk is due primarily to a combination of multiple types of fast-moving landslides, including rock falls, rock slides, and debris flows. In the Campania Region (\# 15), harmful landslides concentrate in the area surrounding the Vesuvius volcano, and are chiefly soil slides, debris flows, and debris avalanches that involve loose volcanic materials (secondary lahars). In Piedmont Region (\# 2), harmful floods occur mostly along large rivers, whereas in Sicily (\# 19) flood casualties are caused chiefly by flash floods along ephemeral streams.

\section{Conclusions}

We exploited a new catalogue of landslide and flood events with direct consequences to the population of Italy, to update existing estimates of societal (collective) landslide and flood risk in Italy (Salvati et al., 2003; Guzzetti et al., 2005a, b), and to obtain new estimates for the 20 Italian Regions. Studying the geographical distribution of sites where landslides and floods have caused direct damage to the population, and the temporal pattern and distribution of the damaging events, we have found that harmful landslide and flood events are not distributed homogeneously in Italy. By ranking the events with casualties in each Region on their intensity, measured by the total number of casualties (i.e., deaths, missing persons, and injured people) in an event, we have found that the relationship to link the intensity of the event to its rank in the catalogue obeys a negative power law. Based on this result, we modelled the landslide and flood casualty data using a Zipf distribution, which proved capable of representing the casualty data in Italy. We argue that the same distribution can be used to model casualty (or fatality) data elsewhere. Analysis of the scaling exponents $s$ of the Zipf distributions obtained for the 20 individual Regions in Italy allowed for comparing societal landslide and flood risk in different geographical areas, and for different periods. Finally, to rank the 20 Italian Regions on their collective landslide and flood risk levels, we prepared plots of the frequency of the harmful events versus the intensity of the events. Analysis of the plots revealed that societal landslide risk in Italy is highest in Trentino-Alto Adige and Campania Regions and lowest in the Emilia-Romagna Region, and that collective flood risk is largest in the Piedmont and in Sicily Regions, and lowest in the Umbria and Basilicata Regions. 
Acknowledgements. We thank J. Coe and a second anonymous reviewer for their constructive comments. We are grateful to the people who contributed to the compilation of the AVI catalogue and who maintain the information system on geo-hydrological catastrophes in Italy (SICI, http://sici.irpi.cnr.it). This work was partially supported by the Italian National Department for Civil Protection (DPC). PS, CB and MR supported by DPC grants.

Edited by: K.-T. Chang

Reviewed by: J. Coe and another anonymous referee

\section{References}

Esposito, E., Porfido, S., Violante, C., and Alaia, F.: Disaster induced by historical floods in a selected coastal area (Southern Italy), in: Proceedings of the Workshop PHEFRA (Palaeofloods, Historical Data and Climatic Variability), Barcelona, Spain, October 2002, edited by: Thorndycraft, V. R., Benito, G., Barriendos, M., and Llasat, M. C., Application in Flood Risk Assessment, 143-148, 2003.

Fell, R. and Hartford, D.: Landslide risk management, in: Landslide risk assessment, edited by: Cruden, D. M. and Fell, R., Balkema, Rotterdam, 51-109, 1997.

Fisher, R. A.: On the mathematical foundations of theoretical statistics, Philos. T. R. Soc. Lond., 222, 309-368, 1922a.

Fisher, R. A.: The goodness of fit of regression formulae, and the distribution of regression coefficients, J. R. Stat. Soc., 85(4), 597-612, 1922 b.

Guzzetti, F.: Landslide fatalities and evaluation of landslide risk in Italy, Eng. Geol., 58, 89-107, 2000.

Guzzetti, F.: Landslide Hazard and Risk Assessment, Ph.D. thesis, Mathematisch-Naturwissenschaftlichen Fakultät der Rheinischen Friedrich-Wilhelms-Universität University of Bonn, Bonn, 389 pp., available at: http://hss.ulb.uni-bonn.de/diss_online/ math_nat_fak/2006/guzzetti_fausto/ (last access: 8 March 2010), 2006.

Guzzetti, F. and Tonelli, G.: Information system on hydrological and geomorphological catastrophes in Italy (SICI): a tool for managing landslide and flood hazards, Nat. Hazards Earth Syst. Sci., 4, 213-232, 2004,

http://www.nat-hazards-earth-syst-sci.net/4/213/2004/.

Guzzetti, F., Cardinali, M., and Reichenbach, P.: The AVI Project: A bibliographical and archive inventory of landslides and floods in Italy, Environ. Manage., 18(4), 623-633, 1994.
Guzzetti, F., Salvati, P., and Stark, C. P.: Evaluation of risk to the population posed by natural hazards in Italy, in: Landslide risk management, edited by; Hungr, O., Fell, R., Couture, R., and Eberhardt, E., Taylor \& Francis Group, London, 381-389, 2005a.

Guzzetti, F., Stark, C. P., and Salvati, P.: Evaluation of flood and landslide risk to the population of Italy, Environ. Manage., 36(1), 15-36, 2005b.

Kolmogorov, A.: Grundbegriffe der Wahrscheinlichkeitsrechnung, Julius Springer, Berlin, 1933.

Newman, M. E. J.: Power laws, Pareto distributions and Zipf's law, Contemp. Phys., 46(5), 323-351, 2005.

Porfido, S., Esposito, E., Alaia, F., Molisso, F., and Sacchi, M.: The use of documentary sources for reconstructing flood chronologies on the Amalfi rocky coast (southern Italy), in: Geohazard in rocky coastal area, The Geological Society, London, Special Publications, 322, edited by: Violante, C., The Geological Society of London, 173-187, 2009.

Reed, W. J.: The Pareto, Zipf and other power laws, Econ. Lett., 74(1), 15-19, 2001.

Rossi, M., Witt, A., Guzzetti, F., Malamud, B. D., and Peruccacci, S.: Analysis of historical landslide time series in the EmiliaRomagna Region, Northern Italy, Earth Surf. Proc. Land., 2010.

Salvati, P., Bianchi, C., and Guzzetti F.: Catalogo delle Frane e delle Inondazioni Storiche in Umbria, CNR IRPI e Fondazione Cassa di Risparmio di Perugia, ISBN-10 88-95172-00-0, ISBN-13 97888-95172-00-2, 278 pp., 2006 (in Italian).

Salvati, P., Guzzetti, F., Reichenbach, P., Cardinali, M., and Stark, C. P.: Map of landslides and floods with human consequences in Italy, CNR Gruppo Nazionale per la Difesa dalle Catastrofi Idrogeologiche Publication n. 2822, scale 1:1 200 000, 2003.

Smirnov, N.: Estimate of deviation between empirical distribution functions in two independent samples, Bulletin of Moscow University, 2(2), 3-16, 1933.

White, E. P., Enquist, B. J., and Green, J. L.: On estimating the exponent of power-law frequency distributions, Ecology, 89(4), 905-912, doi;10.1890/07-1288.1, 2008.

Wilk, M. B. and Gnanadesikan, R.: Probability plotting methods for the analysis for the analysis of data, Biometrika, 55(1), 1-17, 1968. 